\title{
PENGARUH GAYA KOMUNIKASI DAN GAYA KEPEMIMPINAN ASTA BRATA TERHADAP KINERJA BENDESA ADAT DI DESA ADAT BULELENG
}

\author{
Kadek Tedy Mandala Putra $\underline{\text { a.1 }}$ \\ I Nyoman Yoga Segara a \\ Ida Ayu Tary Puspa a \\ a Universitas Hindu Negeri I Gusti Bagus Sugriwa Denpasar \\ 1 Corresponding Author, email: : tedymandalaputra@gmail.com (Putra)
}

\section{ARTICLE INFO}

\section{Article history:}

Received: 19-07-2021

Revised: 18-08-2021

Accepted: 10-09-2021

Published: 30-09-2021

Keywords:

Leadership style, communication

style, asta brata, bendesa adat
ABSTRACT

This study aims to: (1) analyze the influence of Asta Brata's communication style and leadership style on the performance of the Bendesa Adat in the Buleleng Traditional Village, Buleleng District, Buleleng Regency; (2) describe the influence of communication style on the performance of the Bendesa Adat Buleleng; and (3) describe the influence of Asta Brata's leadership style on the performance of the Bendesa Adat Buleleng. This study uses a quantitative research design that uses the type or form of research that uses statistical calculations carried out through field data collection to Prajuru Desa and community leaders and the method used is the survey method. The data collection technique used is a questionnaire and then analyzed using regression analysis with the aim of determining the causal relationship between one variable and another. The results of the study show that communication style has a significant effect on the performance of the Bendesa Adat. The percentage of the contribution of the partial influence of the communication style variable on the performance of the traditional village leader is $60 \%$. Then the leadership of Asta Brata has a significant effect on the performance of the Bendesa Adat. The percentage of the contribution of the partial influence of the Asta Brata leadership style variable on the performance of the traditional village leader is $30 \%$. And the communication style and leadership style of Asta Brata have a significant effect on the performance of the Bendesa Adat. The percentage contribution of the simultaneous influence between the variables of communication style and Asta Brata's leadership style on the performance of the Bendesa Adat is 68\%.

\section{PENDAHULUAN}

Lingkup pengelolaan suatu wilayah memiliki sistem etnografi, yang dibentuk oleh Desa-desa Adat di suatu wilayah seperti Bali. Desa adat terdiri dari beberapa banjar adat, dan beberapa desa hanya terdiri dari satu banjar adat. Desa adat berbeda dengan desa dinas dalam hal definisi, struktur organisasi, tanggung jawab dan kewenangan. Di Provinsi Bali Nomor: 03/2001 tentang Desa Adat, ditetapkan bahwa Desa Adat adalah kesatuan masyarakat hukum adat di Provinsi Bali, yang memiliki kesatuan tradisi dan gaya hidup sosial yang diwariskan secara turun-temurun dalam masyarakat Hindu. Hubungan Kahyangan Tiga atau Kahyangan Desa memiliki wilayah dan harta tertentu, memiliki 
kekayaan, dan berhak mengurus keluarga sendiri. Selain Desa Adat, peraturan daerah juga menjelaskan Desa Adat yang merupakan kelompok masyarakat dan bagian dari Desa Adat.

Melihat aktivitas kegiatan Bendesa Adat Buleleng yang selalu megedepankan ajaran Dharma dalam mengatur tata kelola organisasi adat di wilayahnya. Pelaksanaan kerja yang dilakukan Bendesa Adat Buleleng yaitu melakukan interaksi alias terjun langsung ke masyarakat dalam mengatasi masalah adat yang ada, serta memiliki sifat terbuka guna memperlancar proses komunikasi dalam penanganan masalah adat di dalamnya. Komunikasi Bendesa Adat Buleleng menggunakan pola komunikasi vertikal dan horizontal, serta melakukan audiensi maupun musyawarah mufakat bersama jajaran bawahannya. Terkait penyebaran informasi, Bendesa Adat Buleleng rutin menginfokan informasi lewat sosial media, serta eksis dan update dalam melakukan aktivitas kerja Bendesa Adat di sosial media untuk memberitahu khalayak atau publikasi terkait kinerja yang di lakukan Bendesa Adat di daerahnya. Kepemimpinan beliau sangat energik, serta megedepankan gaya kepemimpinan yang bersifat saling mengajak, merangkul dan mendorong sesama agar dapat bekerja dengan baik. Dalam hal ini selaras dengan ajaran Asta Brata seperti konsep dari Matahari (Dewa Surya) sebagai sumber kemakmuran beserta kehidupan yang memberikan cahayanya guna kesejahteraan.

Spirit Desa Adat mengandung makna ajaran agama Hindu. Windia, dkk (2019:15), "mengatakan unsur-unsur Desa Adat terdiri atas; (1) Parahyangan, yaitu pura/tempat suci agama Hindu dengan segala prasarana dan aktivitas. (2) Pawongan, yaitu warga desa bersangkutan (yang beragama Hindu). (3) Palemahan, yaitu pemanfaatan lingkungan alam yang bernuansa Hindu dan hukum adat Bali. Tugas dan wewenang Desa Adat erat kaitannya dengan pelaksanaan ajaran agama Hindu dalam kehidupan bermasyarakat adat di Bali". Dalam pengaplikasian di lapangan, ada torehan kinerja yang dilakukan Bendesa Adat Buleleng diantaranya; penataan wewidangan Setra Adat Buleleng seperti pembangunan wantilan, penataan tempat pembakaran mayat/layon (Pamuunan), pembangunan tempat pembakaran layon bagi Sulinggih, pembangunan tempat Kremasi yang berbasis gotong royong dan Pasraman Kilat yang berbasis budaya, serta ditampilkan setiap bulan sekali yang berjuluk "Wantilan Berdaya, Krama Berbudaya. Selain itu juga dalam hubungan konsep Tri Hita Karana, Bendesa Adat Buleleng melakukan terobosan membuat lubang resapan Biopori di ketiga kawasan Pura Kahyangan Tiga sebagai wujud kepedulian lingkungan yang bersih dan asri di tempat suci.

Windia, Sudiana dan Relin (2019:20-21), "mengutarakan tugas dan wewenang Bendesa Adat dan kelihan banjar yaitu berhubungan dengan tugas dan wewenang dari Desa Adat (pelaksanaan ajaran agama Hindu dalam kehidupan masyarakat adat di bali), berdasarkan hukum Hindu, hukum adat bali (terutama awig-awig Desa Adat) dan dalam beberapa hal juga berdasarkan konstitusi UUD 1945 dalam wadah NKRI". Dalam awig-awig Desa Adat, tugas dan tanggung jawab Bendesa Adat diterapkan sebagai "Swadharmaning Bendesa Adat luire: Ha. Ngemargiang sedaging awig-auwig miwah perarem desa. Na. Nuntun tur ngenterang krama rawuhing warga desa ngupadi anut petitis; Ca. Mawosin kalih niwakang pemutus marep ring wicara warga desa; Ra. Maka duta metemuang bawos ring sapa sira ugi dan prade prejuru utawi dulu iwang penglaksana keni pemidanda nikel ring keiwangan soang-soang krama saha keangkat kerariyanang manut pararem." Semua kegiatan dan ritual yang 
dilakukan di Desa Adat sebagian besar melibatkan gaya/budaya desa dan harus disetujui oleh perangkat Desa Adat (Bendesa Adat) atau diketahui oleh masyarakat adat dalam arti krama desa.

Berdasarkan uraian konteks masalah di atas, maka perlu dilakukan kajian penelitian yang komprehensif yang dijabarkan di bawah dengan judul "Pengaruh Gaya Komunikasi dan Gaya KepemimpinanAsta Brata Terhadap Kinerja Bendesa Adat di Desa Adat Buleleng Kecamatan Buleleng Kabupaten Buleleng".

\section{METODE PENELITIAN}

Penelitian ini dilakukan untuk menganalisis pengaruh komunikasi dan gaya kepemimpinan Asta Brata terhadap kinerja kepemimpinan Bendesa Adat. Survei ini menggunakan desain survei kuantitatif dengan menggunakan jenis atau format survei dengan menggunakan perhitungan statistik yang dilakukan melalui pengumpulan data di lapangan oleh Prajuru Desa dan tokoh masyarakat dan Metode yang digunakan adalah metode survey.

Dalam penelitian ini menggunakan independent variable (variabel bebas) yakni gaya komunikasi dan gaya kepemimpinan Asta Brata dan menggunakan satu variabel terikat (dependent variable) yaitu kinerjaBendesa Adat.

Jenis data untuk survei ini menggunakan data kualitatif yang dikuantifikasi sebagai hasil survei, sedangkan sumber data penelitian dibagi ke dalam dua kategori, yaitu data primer dan data sekunder. Data primer dalam penelitian ini yakni berupa persepsi Prajuru Desa serta tokoh masyarakat yang di nilai dari kuesioner penelitian. Data sekunder dalam penelitian ini yakni data yang didapatkan dari instansi adat berupa rekapitulsi data Desa Adat dan Banjar Adat di Kecamatan Buleleng.

Teknik dalam pengumpulan data yang digunakan untuk memperoleh data yang dibutuhkan dalam penelitian ini adalah teknik kuesioner. Penelitian ini merupakan penelitian sampel. Pengambilan sampel menggunakan metode simple random sampling.

Instrumen penelitian ini adalah kuesioner yang berisi daftar pernyataan yang akan disebarkan kepada responden, dalam hal ini adalah Prajuru Desa serta tokoh masyarakat. Kuesioner akan dirancang menggunakan skala likert dengan lima poin. Untuk menguji instrumen penelitian dilakukan uji validasi dan uji reliabiltas sebelum data dianalisis lebih lanjut.

Tabel 4.1 Rincian Pendistribusian Kuesioner

\begin{tabular}{|l|c|}
\hline \multicolumn{1}{|c|}{ Keterangan } & Jumlah \\
\hline Angket yang dikirim & 55 \\
\hline Angket yang kembali & 50 \\
\hline Angket yang tidak kembali & 5 \\
\hline Angket yang dapat diolah & 50 \\
\hline Tingkat Pengembalian Angket $(50 / 55 \times 100 \%)$ & $90 \%$ \\
\hline Tingkat Pengembalian yang diolah & $90 \%$ \\
\hline
\end{tabular}


Data diolah menggunakan bantuan SPSS (Statistical Package for the Social Sciences) untuk mengetahui tingkat hubungan atau pengaruh antara variabel bebas dan variabel terikat secara parsial dan gabungannya atau signifikan masingmasing variabel. Selanjutnya penulis menganalisa dengan menggunakan analisa

\section{HASIL DAN PEMBAHASAN \\ Hasil}

Penelitian dilakukan di Desa Adat Buleleng dengan menyebarkan kuesioner sebanyak 55 buah untuk Prajuru Desa dan tokoh masyarakat yang dijadikan sampel. Rincian pendistribusian statistik, kemudian mengetahui pengaruh gaya komunikasi dan gaya kepemimpinan Asta Brata terhadap kinerja Bendesa Adat. Dalam kajian ini menggunakan analisis regersi dengan tujuan menentukan hubungan sebab akibat antara satu variabel dengan variabel yang lain. dan pengembalian kuesioner serta informasi tingkat pengembalian dapat disajikan pada tabel berikut:

Tabel 4.1 Rincian Pendistribusian Kuesioner

\begin{tabular}{|l|c|}
\hline \multicolumn{1}{|c|}{ Keterangan } & Jumlah \\
\hline Angket yang dikirim & 55 \\
\hline Angket yang kembali & 50 \\
\hline Angket yang tidak kembali & 5 \\
\hline Angket yang dapat diolah & 50 \\
\hline Tingkat Pengembalian Angket $(50 / 55 \times 100 \%)$ & $90 \%$ \\
\hline Tingkat Pengembalian yang diolah & $90 \%$ \\
\hline
\end{tabular}

Pendistribusian Kuesioner disebarkan langsung ke Prajuru Desa dan kepada tokoh masyarakat dari tanggal 17 hingga 30 Mei 2021. Sekitar lima puluh kuesioner dikembalikan dan semuanya diproses. Rasio pentalan jajak pendapat (response rate) dan waktu aktif adalah 90\%, dihitung dengan membagi jumlah jajak pendapat yang dikembalikan (50 kuesioner) dengan total yang dikirim (55 kuesioner). Setelah mendapatkan hasil jawaban kuesioner dari responden, maka dilakukan tahap pengolahan data melalui aplikasi SPSS. Selain itu, model persamaan regresi harus menjalani uji asumsi klasik karena dianalisis dengan metode regresi. Model regresi yang baik adalah yang tidak memiliki masalah data berdistribusi normal, masalah multikolinearitas, dan masalah varians variabel. Uji hipotesis klasik yaitu uji normalitas, uji multikolinearitas, dan uji heteroskedastisitas.

Adapun hasil uji asumsi klasik penelitian ini adalah sebagai berikut: 
Tabel 4.1.1 Uji Normalitas

One-Sample Kolmogorov-Smirnov Test

\begin{tabular}{|c|c|c|}
\hline & & $\begin{array}{l}\text { Unstandardized } \\
\text { Residual }\end{array}$ \\
\hline $\mathrm{N}$ & & 50 \\
\hline Normal Parameters ${ }^{a, b}$ & Mean & .0000000 \\
\hline & Std. & 6.31279311 \\
\hline Extreme & Absolute & .127 \\
\hline Differences & Positive & .055 \\
\hline & Negative & -.127 \\
\hline Kolmogorov-Smirnov $Z$ & & .896 \\
\hline Asymp. Sig. (2-tailed) & & .398 \\
\hline
\end{tabular}

a. Test distribution is Normal.

b. Calculated from data.

Berdasarkan hasil analisis pada Tabel 4.1.1 disimpulkan bahwa model persamaan regresi didapat nilai signifikansi sebesar 0,398 yang lebih tersebut berdistribusi normal.

besar dari 0,05. Oleh karena nilai signifikansi uji Adapun hasil uji multikolinieritas dapat Kolmogorov-Smirnov lebih dari 0,05, maka dapat dilihat pada tabelberikut:

Tabel 4.1.2 Hasil Uji Multikolenieritas

\begin{tabular}{|l|c|c|c|}
\hline \multicolumn{1}{|c|}{ Variabel } & Tolerance & VIF & Keterangan \\
\hline Gaya Komunikasi $\left(\mathrm{X}_{1}\right)$ & 0,885 & 1,130 & $\begin{array}{c}\text { Bebas } \\
\text { multikolinieritas }\end{array}$ \\
\hline $\begin{array}{l}\text { Gaya Kepemimpinan } \text { Asta } \\
\text { Brata }\left(\mathrm{X}_{2}\right)\end{array}$ & 0,885 & 1,130 & $\begin{array}{c}\text { Bebas } \\
\text { multikolinieritas }\end{array}$ \\
\hline
\end{tabular}

Berdasarkan Tabel 4.1.2 dapat dilihat berarti model persamaan regresi bebas dari bahwa nilai tolerance untuk setiap variabel lebih multikolinearitas. besar dari $10 \%$ dan nilai VIF kurang dari 10 yang 
Hasil pengujian heteroskedastisitas disajikan pada Tabel dibawah ini:

Coefficients $^{\mathbf{a}}$



a. Dependent Variabel: ABS_RES

Pada Tabel 4.1.3 dapat dilihat bahwa nilai signifikansi dari variabel Gaya Komunikasi sebesar 0,485 dan Gaya Kepemimpinan Asta Brata sebesar 0,077. Nilai tersebut lebih besar dari 0,05 yang berarti tidak terdapat pengaruh antara variabel bebas terhadap absolute residual. Dengan demikian model yang dibuat tidak mengandung gejala heteroskedastisitas.

Adapun hasil uji linieritas dapat dilihat pada tabel berikut;

\section{Tabel 4.2.1 Hasil Uji Linieritas Gaya Komunikasi terhadap Kinerja Bendesa Adat ANOVA Tabel}

\begin{tabular}{|c|c|c|c|c|c|c|c|}
\hline & & & $\begin{array}{l}\text { Sum of } \\
\text { Squares }\end{array}$ & $d f$ & $\begin{array}{c}\text { Mean } \\
\text { Square }\end{array}$ & $F$ & Sig. \\
\hline \multirow{5}{*}{$\begin{array}{l}\text { Gaya } \\
\text { Komunikasi * } \\
\text { Kinerja Bendesa } \\
\text { Adat }\end{array}$} & Between & (Combined) & 3110.893 & 20 & 155.545 & 2.093 & .034 \\
\hline & Groups & Linearity & 2634.697 & 1 & 2634.697 & 35.445 & .000 \\
\hline & & $\begin{array}{l}\text { Deviation from } \\
\text { Linearity }\end{array}$ & 476.196 & 19 & 25.063 & .337 & .992 \\
\hline & Within $G l$ & & 2155.607 & 29 & 74.331 & & \\
\hline & Total & & 5266.500 & 49 & & & \\
\hline
\end{tabular}

Berdasarkan hasil analisis pengaruh Gaya Komunikasi Terhadap Kinerja Bendesa Adat diperoleh nilai signifikasi deviation from liniarity sebesar 0,992 >0,05 mengindikasikan bahwa ada hubungan yang linieritas antara Gaya Komunikasi Terhadap Kinerja Bendesa Adat.Tabel 4.2.2 Hasil Uji Linieritas Gaya Kepemimpinan Asta Brata Terhadap 
Kinerja Bendesa Adat

ANOVA Tabel

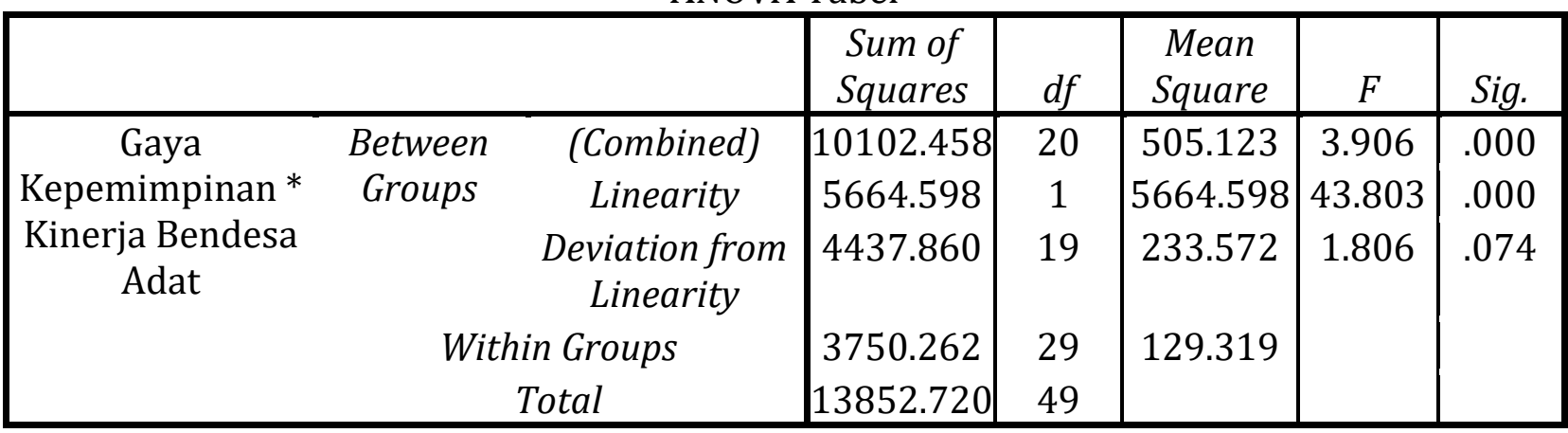

Berdasarkan hasil analisis pengaruh Gaya Kepemimpinan Asta Brata Terhadap Kinerja Bendesa Adat diperoleh nilai signifikasi deviation from liniarity sebesar 0,074 > 0,05 mengindikasikan bahwa ada hubungan yang linieritas antara Gaya Kepemimpinan Asta Brata terhadap Kinerja Bendesa Adat.

Setelah semua asumsi klasik terpenuhi, langkah selanjutnya adalah menyajikan hasil analisis regresi linier berganda. Perhitungan koefisien regresi linier banyak dilakukan dengan analisis regresi menggunakan software SPSS 22.0 for Windows. Hasilnya ditunjukkan pada tabel di bawah ini:

Tabel 4.3.1 Hasil Analisis Regresi Linear Berganda

Coefficients ${ }^{\mathrm{a}}$

\begin{tabular}{|c|c|c|c|c|c|c|}
\hline \multirow{2}{*}{\multicolumn{2}{|c|}{ Model }} & \multicolumn{2}{|c|}{$\begin{array}{c}\text { Unstandardized } \\
\text { Coefficients }\end{array}$} & \multirow{2}{*}{$\begin{array}{c}\text { Standardized } \\
\text { Coefficients }\end{array}$} & \multirow[b]{2}{*}{$l$} & \multirow[b]{2}{*}{ Sig. } \\
\hline & & $B$ & Std. Error & & & \\
\hline \multirow[t]{3}{*}{1} & (Constant) & 37.554 & 9.201 & & 4.082 & .000 \\
\hline & Gaya Komunikasi & .597 & .094 & .554 & 6.320 & .000 \\
\hline & Gaya Kepemimpinan & .300 & .058 & .451 & 5.148 & .000 \\
\hline
\end{tabular}

a. Dependent Variabel: Kinerja Bendesa Adat

Berdasarkan hasil analisis regresi linier berganda seperti yang disajikan pada Tabel 4.3.1, maka dapat dibuat persamaan regresi sebagai berikut:

$$
\mathrm{Y}=37,554+0,597 \mathrm{X} 1+0,300 \mathrm{X} 2+\mathrm{e}
$$

Nilai koefisien regresi untuk masingmasing variabel bebas memiliki nilai uji $\mathrm{t}$ signifikan lebih kecil dari 0,05. Hal ini menunjukkan bahwa semua variabel independen memiliki pengaruh yang besar terhadap variabel dependen.

Adapun hasil uji koefisien determinasi dapat dilihat pada tabel dibawah ini: 
Tabel 4.3.1.1 Hasil Uji Koefisien Determinasi ( $\left.\mathrm{R}^{2}\right)$

\begin{tabular}{|l|c|c|c|c|}
\hline Model & $R$ & $R$ Square & Adjusted R Square & $\begin{array}{c}\text { Std. Error of the } \\
\text { Estimate }\end{array}$ \\
\hline 1 & $.825^{\mathrm{a}}$ & .680 & .667 & 6.44571 \\
\hline
\end{tabular}

Hasilnya ditunjukkan ketika nilai $\mathrm{R}^{2}$ (koefisien determinasi yang disesuaikan) adalah 0,680. Artinya, $68 \%$ variabilitas kinerja asli Bendesa Adat dapat dipengaruhi secara signifikan oleh variabel komunikasi dan gaya kepemimpinan Asta Brata, dan sisanya $32 \%$ dijelaskan oleh faktor-faktor yang tidak dijelaskan dalam model penelitian.

Adapun hasil uji pengaruh antar variabel dapat dijelaskan sebagai berikut:Tabel 4.4.1 Uji Parsial

Coefficients $^{\mathrm{a}}$

\begin{tabular}{|c|c|c|c|c|c|c|}
\hline \multirow{2}{*}{\multicolumn{2}{|c|}{ Model }} & \multicolumn{2}{|c|}{ Unstandardized Coefficients } & \multirow{2}{*}{$\begin{array}{c}\begin{array}{c}\text { Standardized } \\
\text { Coefficients }\end{array} \\
\text { Beta }\end{array}$} & \multirow[b]{2}{*}{$T$} & \multirow[b]{2}{*}{ Sig. } \\
\hline & & $B$ & Std. Error & & & \\
\hline \multirow[t]{3}{*}{1} & (Constant) & 37.554 & 9.201 & & 4.082 & .000 \\
\hline & Gaya Komunikasi & .597 & .094 & .554 & 6.320 & .000 \\
\hline & Gaya Kepemimpinan & .300 & .058 & .451 & 5.148 & .000 \\
\hline
\end{tabular}

a. Dependent Variabel: Kinerja Bendesa Adat

Berdasarkan hasil uji parsial pada Tabel 4.4.1, maka dapat dijelaskan pengaruh antar variabel sebagai berikut;

Berdasarkan hasil analisis pengaruh Gaya Komunikasi terhadap Kinerja Bendesa Adat diperoleh nilai signifikasi sebesar 0,000 dengan nilai thitung sebesar 6,320 dan nilai koefisien regresi positif sebesar 0,597 . Nilai Signifikansi $0,000<0,05$ mengindikasikan bahwa $\mathrm{H}_{0}$ ditolak dan $\mathrm{H}_{\mathrm{i}}$ diterima. Hasil ini mempunyai arti bahwa Gaya Komunikasi berpengaruh signifikan terhadap Kinerja Bendesa Adat.

Berdasarkan hasil analisis pengaruh Gaya Kepemimpinan Asta Brata Terhadap Kinerja Bendesa Adat diperoleh nilai signifikansi sebesar 0,000 dengan nilai thitung sebesar 5,148 dan nilai koefisien regresi positif sebesar 0,300. Nilai
Signifikansi $0,000<0,05$ mengindikasikan bahwa $\mathrm{H}_{0}$ ditolak dan $\mathrm{H}_{\mathrm{i}}$ diterima. Hasil ini mempunyai arti bahwa Gaya Kepemimpinan Asta Brata berpengaruh signifikan terhadap Kinerja Bendesa Adat.

Pengaruh gaya komunikasi, gaya kepemimpinan Asta Brata dan variabel uji valensian terhadap kinerja Bendesa Adat diuji dalam uji-f (uji simultan). Pengujian simultan bertujuan untuk mengetahui apakah semua variabel independen yang teridentifikasi (gaya komunikasi, gaya kepemimpinan Asta Brata dan nilai valensi) cocok untuk memprediksi kinerja Bendesa Adat secara bersama-sama. Tes ini juga dikenal sebagai F-test, hasil uji-F dalam penelitian ini ditunjukkan pada tabel berikut: 
Tabel 4.4.2 Uji Simultan

\begin{tabular}{|ll|r|r|r|r|r|}
\hline Model & \multicolumn{1}{|c|}{$\begin{array}{c}\text { Sum of } \\
\text { Squares }\end{array}$} & \multicolumn{1}{|c|}{$d f$} & Mean Square & \multicolumn{1}{c|}{$F$} & \multicolumn{1}{c|}{ Sig. } \\
\hline 1 & Regression & 4158.104 & 2 & 2079.052 & 50.041 & $.000^{\text {a }}$ \\
& Residual & 1952.716 & 47 & 41.547 & & \\
& Total & 6110.820 & 49 & & & \\
\hline
\end{tabular}

Berdasarkan hasil uji simultan pada Tabel 4.4.2, maka dapat dijelaskan pengaruh variabel di bawah ini:

Hasil analisis menunjukkan bahwa nilai $\mathrm{F}$ sebesar 50,041 dengan signifikansi 0,000 yang kurang dari $\alpha=0,05$, ini berarti model yang digunakan pada penelitian ini adalah layak. Hasil ini memberikan makna bahwa seluruh variabel independen mampu memprediksi atau menjelaskan fenomena Kinerja Bendesa Adat. Dengan kata lain ada pengaruh signifikan secara simultan dari variabel Gaya Komunikasi dan Gaya Kepemimpinan Asta Brata Terhadap Kinerja Bendesa Adat.

\section{Pembahasan}

Hasil pengujian hipotesis diperoleh bahwa gaya komunikasi berpengaruh signifikan terhadap kinerja Bendesa Adat di Desa Adat Buleleng. Berdasarkan hasil penelitian diatas, faktor yang paling dominan menentukan kinerja Bendesa Adat di Desa Adat Buleleng dari variabel gaya komunikasi, yaitu indikator $\mathrm{X}_{1.10}$ bagian dari dimensi gaya komunikasi the structuring style, dimana hasil nilai Corrected Item-Total Correlation (Uji Reliabilitas) sebesar 0,912 (90\%).

Hasil pengujian hipotesis diperoleh bahwa gaya kepemimpinan Asta Brata berpengaruh signifikan terhadap kinerja Bendesa Adat di Desa Adat Buleleng. Berdasarkan hasil penelitian diatas, faktor yang paling dominan menentukan kinerja Bendesa Adat di Desa Adat Buleleng dari variabel gaya kepemimpinan Asta
Brata, yaitu indikator $\mathrm{X}_{2} .36$ bagian dari dimensi gaya kepemimpinan Asta Brata gaya partisipatif yang meliputi Candra Brata dan Baruna Brata, dimana hasil nilai Corrected Item-Total Correlation (Uji Reliabilitas) sebesar 0,857 (86\%).

Hasil pengujian hipotesis diperoleh bahwa secara simultan variabel gaya komunikasi dan gaya kepemimpinan Asta Brata berpengaruh signifikan terhadap kinerja Bendesa Adat di Desa Adat Buleleng. Hasil penelitian menunujukkan bahwa 68 \% kinerja Bendesa Adat dipengaruhi secara signifikan oleh gaya komunikasi dan gaya kepemimpinan Asta Brata.

Sumbangan pengaruh variabel $\mathrm{X}_{2}$ terhadap $Y$ relatif kecil, dimana $X_{1}$ dan $X_{2}$ tidak bisa berpengrauh secara signifikan sama besar dan pasti dari kedua variabel bebas itu ada yang dominan dan ada yang lebih kecil. Secara kuantitatif $\mathrm{X}_{1}$ berpengaruh $60 \quad \%$ dan $\mathrm{X}_{2}$ berpengaruh $30 \%$, maka ketika kedua variabel digabung gaya komunikasi dan gaya kepemimpinan Asta Brata sama-sama berpengaruh sangat besar terhadap $\mathrm{Y}$ yaitu kinerja Bendesa Adat. Berdasarkan integrasi model variabel diatas, faktor yang paling dominan menentukan kinerja Bendesa Adat di Desa Adat Buleleng dari variabel gaya komunikasi dan gaya kepemimpinan Asta Brata, yaitu: dimensi gaya komunikasi the structuring style dan dimensi gaya kepemimpinan Asta Brata gaya pastisipatif yang meliputi Candra Brata sertaBaruna Brata. 


\section{SIMPULAN}

Berdasarkan hasil uji instrumen, maka dapat ditarik kesimpulan sebagai berikut;

1. Hipotesis pertama diterima dan berpengaruh signifikan terhadap Y, artinya gaya komunikasi berpengaruh signifikan terhadap kinerja Bendesa Adat. Persentase sumbangan pengaruh parsial variabel gaya komunikasi terhadap kinerja bendesa adat sebesar $60 \%$.

2. Hipotesis kedua diterima dan berpengaruh signifikan terhadap Y, artinyagaya kepemimpinan Asta Brata berpengaruh signifikan terhadap kinerja Bendesa Adat. Persentase sumbangan pengaruh parsial variabel gaya kepemimpinan Asta Brataterhadap kinerja bendesa adat sebesar $30 \%$.

3. Hipotesis pertama dan hipotesis kedua secara simultan berpengauh signifikan terhadap Y, artinya gaya komunikasi dangaya kepemimpinan Asta Brata berpengaruh signifikan terhadap kinerja Bendesa Adat. Persentase sumbangan pengaruh simultan antara variabel gaya komunikasi dan gaya kepemimpinan Asta Brata terhadap kinerja Bendesa Adat sebesar $68 \%$.

\section{Implikasi}

Hasil penelitian ini memberikan beberapa implikasi dari hasil hipotesis yang telah didapatkan dan disusun secara sistematis, antara lain;

1. Menerapkan perilaku komunikasi yang ideal bepengaruh terhadap kinerja seorang pemimpin yang mengacu pada bagianbagian dari dimensi gaya komunikasi. Dimensi gaya komunikasi terutama the structuring style sangat signifikan dalam meningkatkan kinerja Bendesa Adat.

2. Gaya kepemimpinan sangat berpengaruh terhadap kinerja, serta mutu dari sebuah kepemimpinan memainkan peranan yang dominan dalam keberhasilan organisasi adat. Meskipun $30 \%$ dan terbesar dari dimensi yang lain, model kepemimpinan Asta Brata signifikan dalam meningkatkan kinerja Bendesa Adat. Bendesa Adat mendorong jajarannya untuk saling berbagi gagasan sekaligus memfasilitasi apa yang dibutuhkan demi tercapainya tujuan bersama. Dalam Kautilya Arthasastra mengenai tujuan proses kepemimpinan itu yaitu "apa yang membuat Raja senang bukanlah kesejahteraan, tetapi yang membuat rakyat sejahtera itulah kebahagiaan seorang Raja". Implikasi dari pernyataan ini bahwa tujuan dan makna kesuksesan sebuah proses kepemimpinan adalah apabila tercipta kesejahteraan bagi seluruh anggota organisasi, bahkan lebih luas adalah kebahagiaan dunia (sukanikang rat).

3. Antara teori gaya komunikasi dan teori gaya kepemimpinan Asta Brata sesuai dengan pengaplikasian teori dan konsep yang diterapkan. Menggambarkan bahwa faktor perilaku komunikasi dan gaya kepemimpinan perlu diperhitungkan, karena secara empiris sangat tepat untuk meningkatkan kinerja Bendesa Adat. Dimensi dan indikator dari konsep gaya komunikasi dan gaya kepemimpinan Asta Brata menjadikan pedoman dan acuan yang sesuai mampu menunjukkan karakter yang subjektif. Nilai budaya lokal Hindu yang terangkum dalam Tri Hita Karana, kepemimpinan secara agama Hindu yang dikenal dengan Asta Brata dan komitmen organisasional tepat berpengaruhnya terhadap kinerja Bendesa Adat. 


\section{DAFTAR PUSTAKA}

Muslih Basthomi 2020. Urgensi Komunikasi Dalam menumbuhkan Motivasi di Pandemi Covid-19.

Budyatna, Muhammad dan Ganiem, Leila Mona. 2012. Teori Komunikasi Antarpribadi. Jakarta : Kencana Prenada Media Group.

Bungin, Burhan. 2011. Sosiologi Komunikasi. Jakarta : Kencana Prenada Media Group.

Cangara, Hafied. 2010. Pengantar Ilmu Komunikasi. Jakarta: Rajawali Pers.

Craib,1986.Teori Sosiologi Modern. Jakarta: PT Raja GravindoPersada.

Evi Zahara. 2018. Peranan Komunikasi Organisasi Bagi Pinpinan Organisasi.

Hamidi. 2004 Metode Penelitian Kualitatif (Aplikasi Praktis Pembuatan Proposal dan Laporan Penelitian) UMM Press: Malang.http://kabarwashliyah.com/2013 /06/30/elit-lokal-bangun-daerah-harusmaksimal.

Widyantara, I Gede Suka (2020) Peranan Bendesa dalam Penyelesaian Sengketa Tanah Waris di Desa Adat Buduk.

I Gusti Ngurah Sudiana, Wayan P Windia, Relin DE. 2016. Prajuru Desa Pekraman Rohaniawan Hindu Dan Hukum, Denpasar: Bali Santi Pusat Pelayanan.

Ida Bagus Yudha Triguna, 2000. Teori Tentang Simbul, Denpasar: Widya Dharma.

Koentjaraningrat, 1990. Pengantar Ilmu Antropologi. Jakarta: Rineka Cipta.

M. N. Nasution, 2004. Manajemen JasaTerpadu, Bogor Ghalia Indonesia. Moleong, Mark dan goodson., 2003.

Metodologi Penelitian Kualitatif . Bandung : Remaja Rosdakarya.

Mulyana, Deddy, 2008. Komunikasi Massa. Bandung : Widya Padjadjaran.

Poerwadarminta. W.J.S. 1987. Kamus Umum Bahasa Indonesia. Jakarta: Pusat Pembinaan dan Pengembangan Bahasa Departemen Pendidikan dan Kebudayaan.
Poloma,M.Margaret, $2003 . \quad$ Sosiologi Kontemporer, Jakarta: Kencana.Pudja, dkk. 1977. Dalam bahasa sansekerta metode dalam pramana . Jakarta: Lembaga Penerjemah Kitab Suci Weda.

Pratiwi, C. A. (2017). Harai: Telaah Konsep Religi Koentjaraningrat. Japanology, 173185.

Puja I Gede, 1982. Siwa Sesana, Jakarta: Proyek Pengaduan Kitab Hindu Departemen Agama.

Puja, G. 1997. Sarasamuscaya. Surabaya: Paramita.

Puloma, Margaret M., 2003. Sosiologi Kontemporer. Jakarta : Raja Grafin

Riswadi, 2009. Pengantar Komunikasi. Yogyakarta: Graha Ilmu. Singarimbun,

Efendi, 1995. Metode Penelitian Survey, Jakarta: PT Pustaka LP3ES.

Suasthawa Dharmayuda, I Made. 2001.Desa Adat (Kesatuan Masyarakat Hukum Adat di Propinsi Bali). Denpasar : Upada Sastra.

Sudirsa, I Komang, 2008. Dampak Tajen Terhadap Kehidupan Keluarga Bebotoh ditinjau dari Ajaran Etika Hindu di Desa Adat Pasedahan, Kecamatan Manggis, Kabupaten Karangasem. Denpasar : IHDN.

Sugiyono. 2016. Metode Penelitian Kuantitatif Kualitatif dan R\&D. Bandung: Alfabeta.

Suranto Aw, 2011 Komunikasi Interpesonal, Yogyakarta: Graha Ilmu.

Surat Edaran Guburnur Bali Nomor: 267/01B/HK/2020. PembatasanSosial Berskala Besar.

Tabroni. 2001. Metodelogi Penelitian Sosial Agama. Bandung : PT Remaja Rosdakarya.

Wayan P.Windia2 (2017) Keberadaan Desa dan Adat Bali Serta Peranan Bendesa Adat. E-Jurnal, Dosen Unud Bali.

Mahendra, Oka. 2001. Ajaran Agama Hindu Tentang Kepemimpinan, Konsep Negara dan Wiweka. Denpasar: Manikgeni. 
Ruliana, Poppy. 2014. Komunikasi Organisasi: Teori dan Studi Kasus. Jakarta: Rajawali Pers.

Sudirga dkk, Ida Bagus. 2004. Widya Dharma Agama Hindu 1, 2 dan 3. Bandung: Ganeca.

Siagian, Sondong. P. 2003. Teori dan Praktek kepemimpinan, Jakarta: PT Rineka Cipta.

Sudarta, W. 2008. Penerapan Tri Hita Karana di Subak Kawasan Perkotaan (Kasus Subak Anggabaya, Kota Denpasar). Denpasar: Jurnal SOCA, Vol. 9, No.2, Juli 2012 Fakultas PE Unud.

Surpha, Wayan. 1993. Eksistensi Desa Adat di Bali. Denpasar: PT. Upada Sastra.

WHO. (2021, juni 13). WHO Coronavirus (COVID-19) Dashboard. Retrieved from WHO Coronavirus (COVID-19) Dashboard: https://covid19.who.int/

Widjaja, A.W. 2000. Ilmu Komunikasi Pengantar Studi. Jakarta: Rineka Cipta 